\title{
Parameter Identification and Effect of Partial Shading on a Photovoltaic System
}

\author{
Amin Hajizadeh $^{1}$ and Jishnu Warrier Anil Kumar ${ }^{1}$ \\ ${ }^{1}$ Department of Energy Engineering, Aalborg University, Esbjerg 6700, Denmark
}

\begin{abstract}
Partial shading cause significant losses to the performance of a photovoltaic (PV) system. So, it is imperative to study effects of partial shading; for that a two-diode model of the experimental setup made. Upon verifying the model with the experimental parameters, a MATLAB/Simulink model is made based on this model. Various shading patterns, the effect of bypass diodes; the effect of overlapping bypass diode is studied on this MATLAB/Simulink model. It is found out that the reduction in power loss is depended on the location of the shaded cell but not the area of the shaded cell. Also, the over-lapping bypass diode configuration has a slight improvement in the PV performance compared to the non-overlapping bypass diode configuration. An experimental test is also conducted by applying different shading pattern and they proves the results are compatible with the simulated results.
\end{abstract}

\section{Introduction}

Most of the present photovoltaic system's efficiency can be increased by the proper optimization. But these optimizations can vary from system to systems since optimization parameters vary according to the geographical conditions. The simplest approach is the one diode model [1]. But in a single diode method, the effect of recombination is neglected which happens in the depletion region [2]. In a two-diode model this effect is considered with the help of the second diode. Iterative programming method is used to calculate the values of $R_{s}$ and $a$ in [3] and in [4] fuzzy logic is used to resolve these values. But in many works the identity factor $a_{1}$ and $a_{2}$ is considered are 1 and 2 respectively which is not correct during every case [5]. Partial shading is the scenario in which one or more solar cell is shaded from the solar irradiation compared to the other cells in a module. Each of the cells in a module is connected in series, the power output from the module will be depended on the level of current passing through the weakest cell. This is one of the characteristics of series the connection. So even a small shading can adversely affect the performance of the system [6]. As a result, the bypass diode controls the voltage drop across the cell [7]. A module without a bypass diode will have greater power loss under shaded the condition when it is compared to a module which has a bypass diode [8].

\section{Two Diode Model}

One of the assumption which is considered in the onediode model is that there is no recombination loss at the depletion region. But in a two-diode model, this effect is also considered. Even though the two-diode model is more complicated, it is more accurate method to model a PV system. The circuit diagram of a two-diode model can be seen in Fig.1. In this model diode one, $D_{1}$ represents the diffusion process while the second diode $D_{2}$ represents the effect of recombination in the cell. The series resistance $R_{S}$ represents the initial losses caused by the current flow and parallel resistance $R_{p}$ represents the modelling of the reverse saturation current. The total current $I$ generated by the system is given by the Eqn.3.

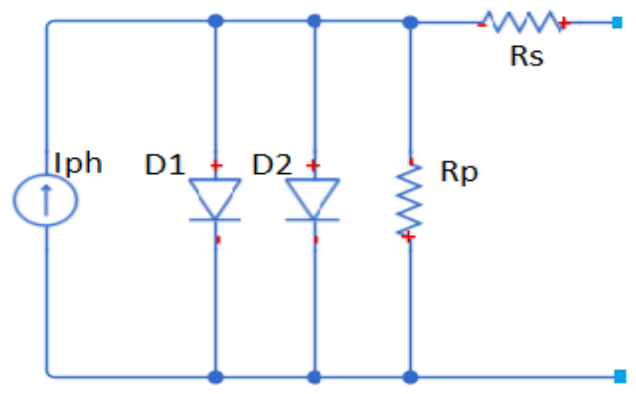

Fig. 1. Two- Diode Model

$$
\begin{aligned}
& B=I_{01} \exp \left(\frac{V+R_{S} I}{V_{t 1} a_{1}}-1\right) \\
& C=I_{02} \exp \left(\frac{V+R_{S} I}{V_{t 2} a_{2}}-1\right) \\
& I=I_{p h}-B-C-\frac{V+I R_{S}}{R_{p}}
\end{aligned}
$$

The terms $B$ and $C$ are used for the convenience. Here $I_{01}$ represents the reverse saturation current through diode one and $I_{02}$ represents are reverse saturation current through the diode two. $V_{T 1}$ and $V_{T 2}=N_{S} k T / q$ are the thermal voltage of the module with $N$ is the number of cells, $q$ is the electron charge and $\mathrm{k}$ is the 
Boltzmann's constant of diode one and two. Also $a_{1}$ represents the ideality factor of diode one and $a_{2}$ represents the ideality factor of diode two. The value of light generated current $I_{p h}$ with respect to the temperature and irradiation is given by the Eqn. 4 which was described in [9].

$$
I_{p h}=\left[I_{s c}+K_{i}\left(T-T_{n}\right)\right] \frac{G}{G_{n}}
$$

Here $K_{i}$ represents the short circuit current coefficient, $T_{n}$ represents the temperature at standard testing condition, $G$ represents the irradiance and $G_{n}$ represents the irradiance at standard testing condition. An assumption is made here as the diode current from diode one $I_{01}$ is equal to the diode current from diode two $I_{02}$.

$$
I_{01}=I_{02}=I_{0}
$$

So, the equation for saturation current for two-diode model is described in [10].

$$
\begin{aligned}
& I_{0}=\frac{I_{S c}+K_{i}\left(T-T_{n}\right)}{D-1} \\
& D=\exp \left[\frac{V_{o c}+K_{v}\left(T-T_{n}\right)}{\frac{a_{1}+a_{2}}{p} V_{T}}\right]
\end{aligned}
$$

The value for ideality factor is assumed as $a_{1}=1$ and $a_{2}=2$ The ideality factor $a_{1}$ represents the diffusion of current components and ideality factor $a_{2}$ represents the recombination of the current components.

\subsection{Calculation of $R_{s}$ and $R_{p}$ values}

Finding the value of $R_{p}$ is a stepwise procedure. The procedure that is used here is like that of [11]. As a first step of finding the value of $R_{p}$, the value of $R_{s}$ is assumed as zero in Eqn.9. By this we get the value of $R_{p}$ and this value of $R_{p}$ is substituted in Eqn.8. The result is cross checked with the $P_{\max }$ value in the data sheet. If the values are different, then it is necessary that the same procedure should be repeated. Each time a very small increment is given for the value of $R_{s}$. This procedure is continued until the value of $P_{\max }$ reaches the $P_{\max }$ value described in the PV module data sheet provided by the manufacturer.

$$
\begin{gathered}
P_{\max }=V_{\max } I \\
R_{p}=\frac{V_{m p}+I_{m p} R_{s}}{I_{p v}-I_{0}\left[E+F-\frac{P_{m}}{V_{m}}\right]} \\
E=\exp \frac{V_{m p}+I_{m p} R_{S}}{V_{T}} \\
F=\exp \frac{V_{m p}+I_{m p} R_{s}}{(p-1) V_{T}+2}
\end{gathered}
$$

The terms $E$ and $F$ are used only for the convenience. Without a substitution the equation for $R_{p}$ is too long to be represented.

\section{Experiment Validation}

To verify the two-diode model, an experimental test is conducted, and an electronic load is used for the experiment. The PV module from which the measurements are made can be seen in Fig.2. Since the location is prone for the temperature changes throughout the year, the experiment is conducted under two different temperatures. An electronic load and MATLAB/Simulink software is used for the experiment. Upon completing the experiment, simulation is conducted in MATLAB/Simulink software under similar temperature and irradiation values as of the experiment. The Table.1 shows the comparison between the experimental values and the simulation values for two different days. In Fig.3 a QQ-plot of has been made for the residual value between the experimental results and the simulated results. The data points almost follow a straight line, hence it is safe to arrive at a conclusion that this is a normal distribution and the model represents the real-world system in a good way.

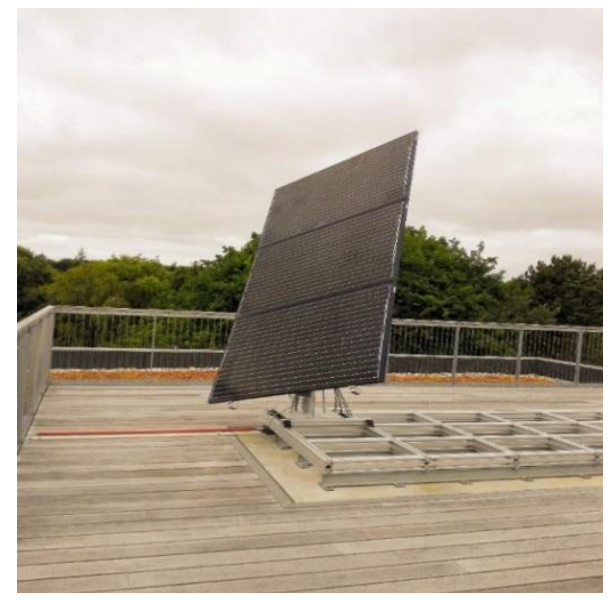

Fig.2. Real PV Module

\section{Shading Effect}

The effect of partial shading is very significant for a photovoltaic system and even a small level of shading can affect the performance adversely [6]. Using the parameters from the two-diode model, a MATLAB/Simulink model is made and the effect of partial shading and effect of number of bypass diodes is analysed. The effect of shading under a series and parallel connections are explained individually. In all the above-mentioned cases the bypass diode configuration is assumed as a non-overlapping configuration.

\subsection{Shading in a series connection}

At first a single module with 60 cells which are connected in series is considered. These cells are subdivided into three strings, i.e. each 20 cells will have one bypass diode which is connected in parallel to them. In the Case A three cells from a string is shaded and the two other strings are unshaded. The simulations are conducted at a temperature of $25^{\circ} \mathrm{C}$ the unshaded irradiation is set to $1000 \mathrm{~W} / \mathrm{m}^{2}$ while the irradiation for shaded cells are $500 \mathrm{~W} / \mathrm{m}^{2}$. The Fig.4 illustrates the shading pattern which is applied for studying. 
Table.1. Comparison of Simulated and experimental data for two different days

\begin{tabular}{|c|c|c|}
\hline & Two-Diode & Experimental \\
\hline \multicolumn{3}{|c|}{ Day 1} \\
\hline $\mathrm{H}$ & 627 & 627 \\
\hline $\mathrm{T}$ & 17 & 17 \\
\hline $\mathrm{I}$ & 17.90 & 17.70 \\
\hline $\mathrm{V}$ & 41.6 & 41.2 \\
\hline $\mathrm{I}$ & 17.041 & 17.184 \\
\hline $\mathrm{V}$ & 32.8 & 32.5 \\
\hline$R_{S}$ & 0.006 & - \\
\hline$R_{p}$ & 32 & - \\
\hline$P_{\max }$ & 558.581 & 554.178 \\
\hline \multicolumn{3}{|c|}{$\mathrm{Day} 2$} \\
\hline $\mathrm{H}$ & 358 & 358 \\
\hline $\mathrm{T}$ & 4 & 4 \\
\hline $\mathrm{I}$ & 10.217 & 10.217 \\
\hline $\mathrm{V}$ & 41 & 41.2 \\
\hline $\mathrm{I}$ & 9.5819 & 9.7165 \\
\hline $\mathrm{V}$ & 36.4 & 36.4 \\
\hline$R_{S}$ & 0.006 & - \\
\hline$R_{p}$ & 32 & - \\
\hline$P_{\max }$ & 348.7453 & 353.6821 \\
\hline & \multicolumn{2}{|c|}{} \\
\hline
\end{tabular}

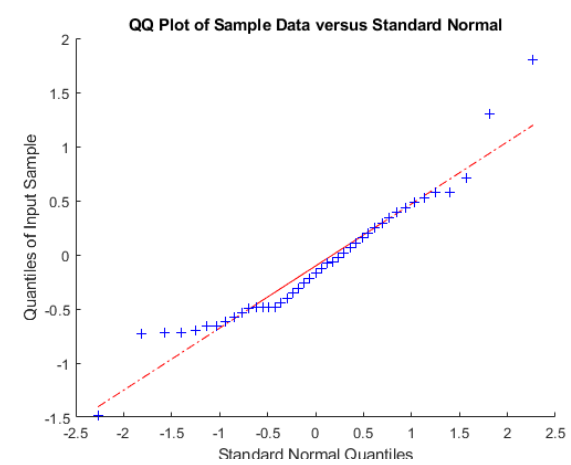

Fig.3. QQ-plot

The Fig.5 and Fig.6 illustrates the PV and IV curve for both Case A and Case B simulations. The blue curve represents the unshaded module. From the IV curve of Case $\mathrm{A}$ it looks as if the entire string has been shaded but it must be noted that only three cells has been shaded. But since the bypass diodes are placed the two unshaded strings operate. From the PV curve the power has reduced by $40 \%$. In Case $\mathrm{B}$, one cell from each of the strings are shared while the rest of the cells are unshaded. In this case bypass diodes have no effect on the strings as all three of them are shaded and due to this the value of current is quite low compared to the previous case.

\subsection{Shading in a parallel connection}

In this case three modules that are connected each other in a parallel connection is considered. This consideration is made because the experimental setup also has the very same configuration, so that it is possible to have a comparison between them. The shading pattern applied here is very similar to that of the shading pattern applied in a series connection. The results of this test can be seen in the Fig. 7 and Fig. 8.

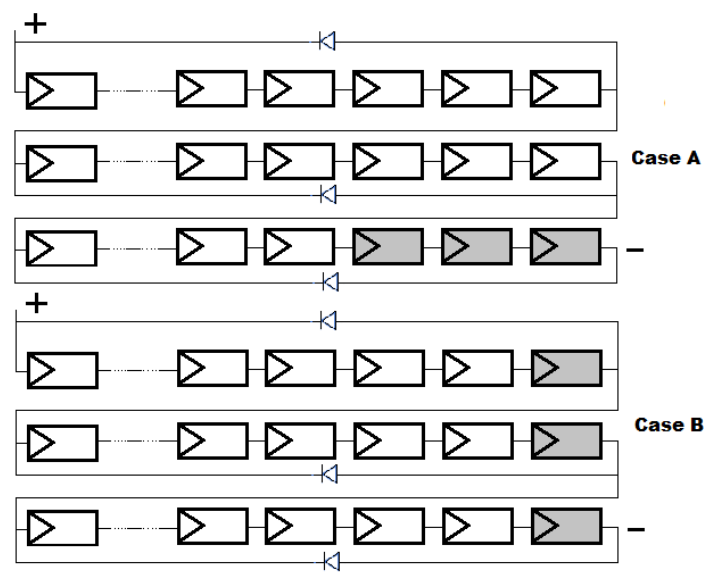

Fig. 4. Shading pattern

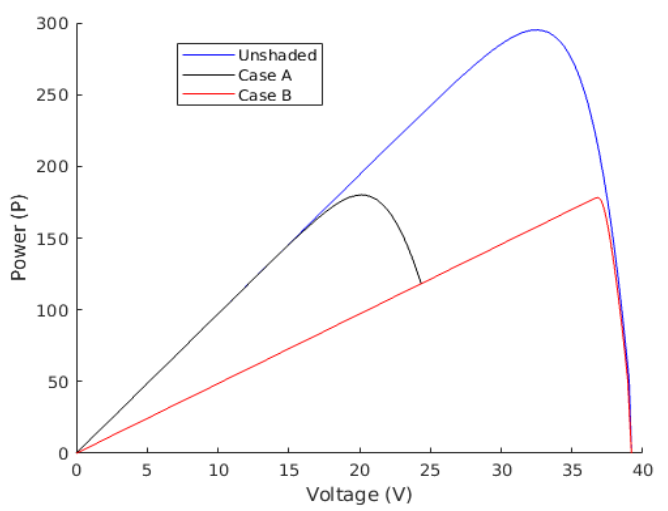

Fig. 5. PV curve when 3 cells from a module is shaded

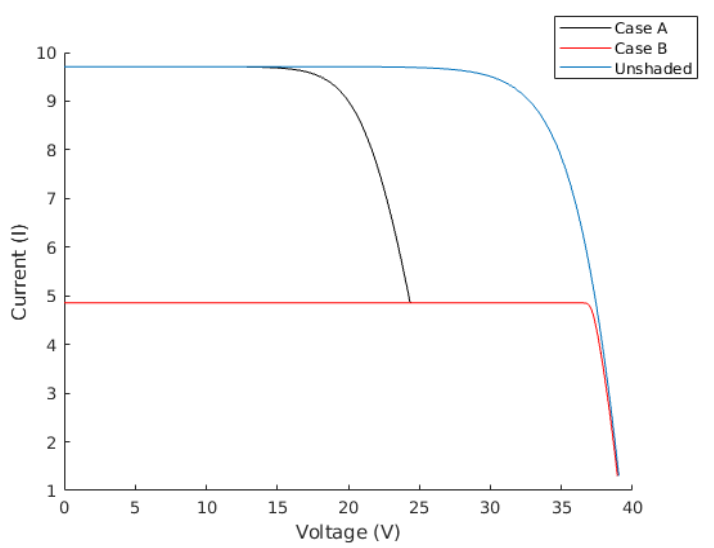

Fig. 6. IV curve when 3 cells from a module is shaded

\subsection{Number of bypass diodes and its effects on parallel connection}

The effect of having bypass diode is studied by considering four cases. A module without a bypass diode will have greater power loss under shaded condition when it is compared to a module which has bypass diode [8]. In Case-A were an entire module is connected to one bypass diode in parallel. In Case-B the module is sub-divided into two strings and two bypass diodes are present here. Case-C consist of a module divided into three strings, meaning three bypass diodes 
are placed. Finally, in Case-D the module is divided into six strings and each string is connected to a bypass diode in parallel. In each of the cases three modules are connected in parallel. This study is done for understand how the number of bypass diodes would affect the performance of the system. The Fig.9 and Fig.10 represents the PV and IV curve when different number of bypass diodes were considered in a parallel connection of modules. It is clear from both the figures that as the number of bypass diodes were increased the performance of both IV and PV curves improved considerable. In each of the cases the number of cell that are partially shaded is six.

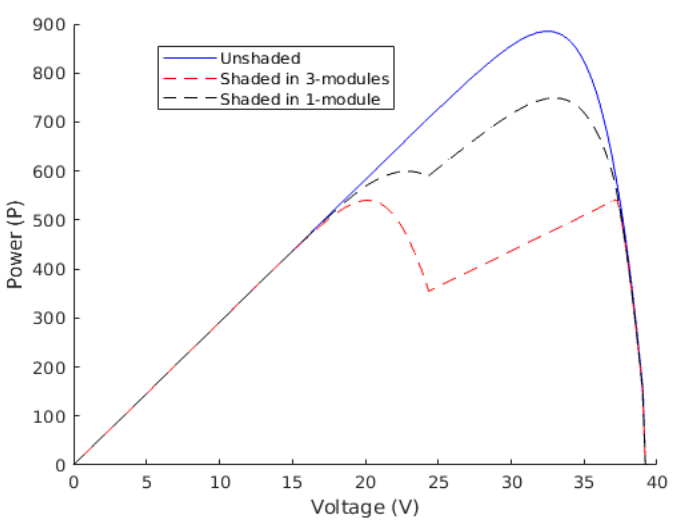

Fig. 7. PV curve when 3 cells shaded in 3 module

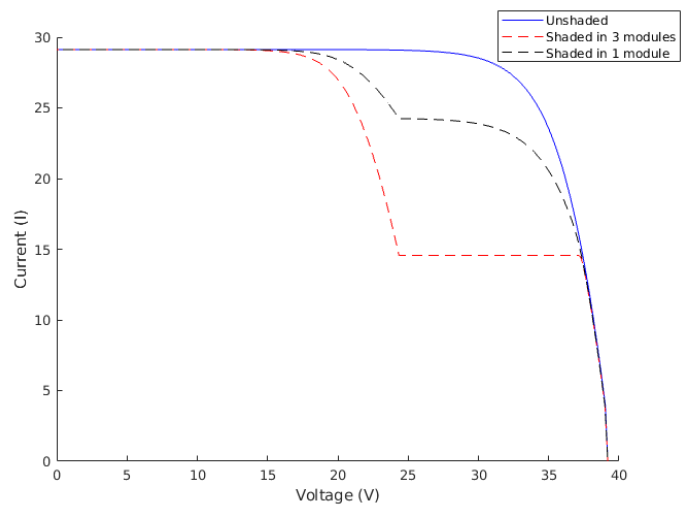

Fig. 8. IV curve when 3 cells shaded in 3 module

From the Table. 2 it can be clearly seen that both the maximum power and fill factor values has increased as more bypass diodes are added into a module. It is evident that for the first three cases the values don't change much but in the fourth case there is a significant increase in both the fill factor value and in the maximum power value.

\subsection{Shading on an overlapping bypass diode}

In an over-lapping bypass diode configuration, some cells inside the module will have an over-lapping bypass diode connection. That means those cells are connected to two bypass diodes. A module of 60 cells are considered with bypass diode BD-1 is connected in parallel between cell $1-29, \mathrm{BD}-2$ is connected between the cell 20-50 and BD-3 is connected between cell 39-60. So according to this configuration the cell between 20-50 are connected to two bypass diodes and this configuration can be seen in Fig.11. It is important to note that under an overlapping configuration it is possible to have three kinds of paths for the current to flow when an overlapping cell is shaded [12].

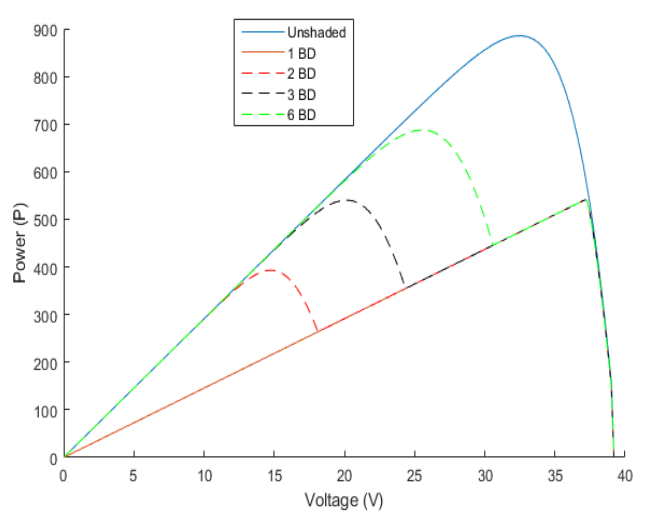

Fig. 9. PV curves of the bypass diode test

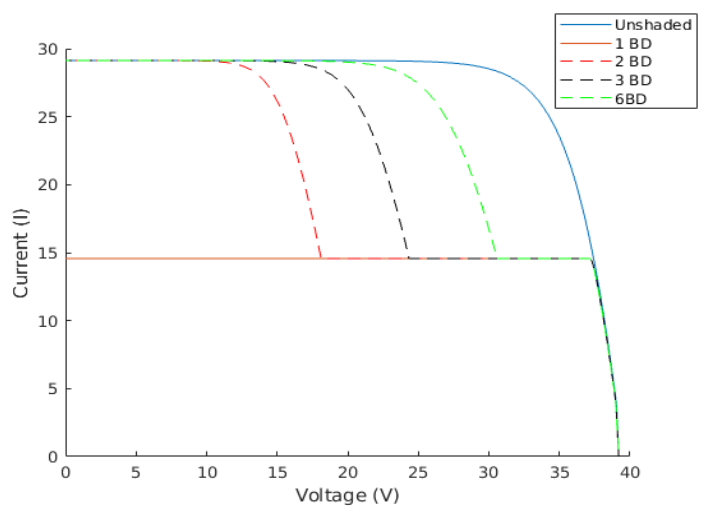

Fig. 10. IV curves of the bypass diode test

Table. 2. Comparing the effect of bypass diodes

\begin{tabular}{|c|c|c|c|c|c|}
\hline & Case A & Case B & Case C & Case D & Case D \\
\hline Imax & 14.54 & 14.55 & 14.69 & 25.14 & 28.1 \\
\hline Vmax & 37 & 37.17 & 37.4 & 26.47 & 32 \\
\hline Pmax & 540.9 & 540.92 & 545.2 & 681.3 & 880 \\
\hline FF & 0.4864 & 0.488 & 0.496 & 0.601 & 0.755 \\
\hline
\end{tabular}

In Fig.12 the IV curve of an overlapping diode configuration and a non-overlapping diode configuration. In this case the shading is done in such a way that two overlapping cells and one non-overlapping cell is shaded. From the Fig.12 the short-circuit current $I_{o c}$ for overlapping is very high than that of the short-circuit current for an unshaded module. This happens because at a low voltage both the BD-1 and BD-2 are conducting at the same time. So, because of this the current value adds up. But as the voltage value increases the BD-1 turns off, as a result the current value drops down. According to [13] this kind of effect only happens in a small-scale system; this effect is not applicable to the large scale photovoltaic systems. 


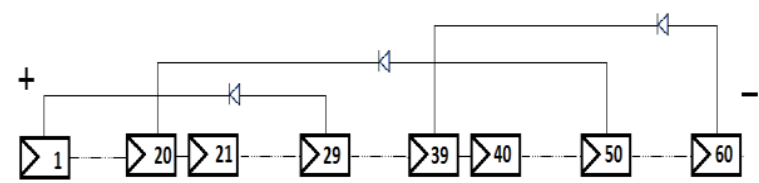

Fig. 11. Shading pattern for overlapping configuration

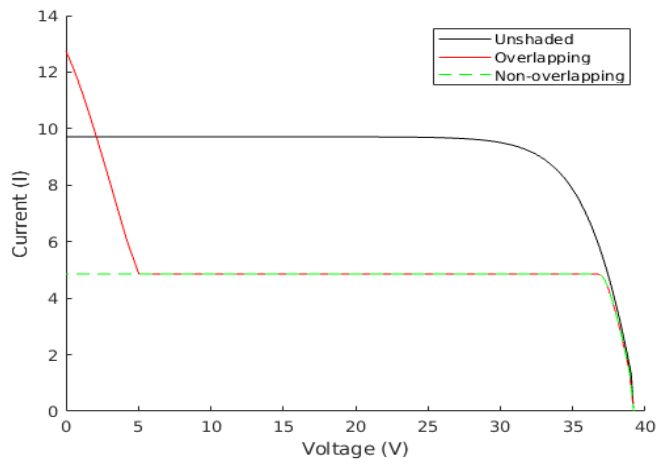

Fig. 12. IV curve under an overlapping bypass diode

\subsection{Experimental Validation of Shading Effect}

The experiment is conducted on a three modules system which are connected in parallel to each other and this setup can be seen in Fig.2 One cell from each module is shaded. Since there are three modules so three cells are shaded as a whole. The cells are shaded using four sheets of papers, this is done to make sure that the cells are not shaded completely. The complete shading is not done due to the fact that in most of the cases the cells are not shaded completely, instead they would be shaded partially. The IV can be seen in Fig.13 and the results are in good terms with the simulated results. While the test was conducted the ambient atmospheric temperature was $16^{\circ} \mathrm{C}$ and the irradiation value was at $681 \mathrm{~W} / \mathrm{m}^{2}$.

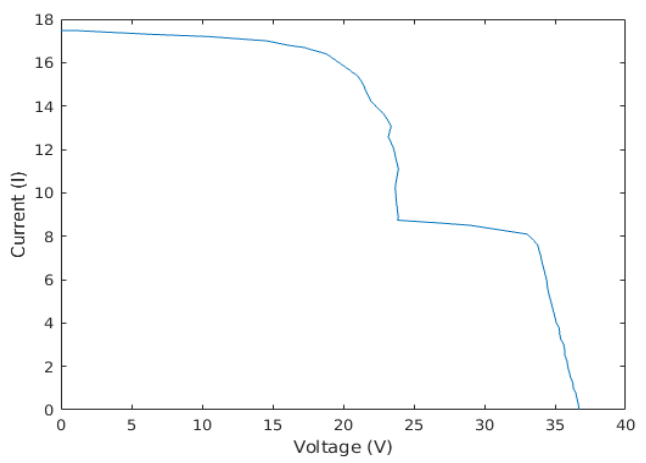

Fig. 13. IV curve of experimental test

\section{Conclusion}

The two-diode model based on the real-world system is made and validated by comparing it to the experimental values. The simulations for partial shading is conducted based on the two-diode model. From these simulations it is understood that the position of the shading has more importance compared to the area of shaded cell. It was observed that the power loss is different by changing the location of the shading effect while the total surface area remains the same. Adding more bypass diodes reduces the effect of shading on a system. Finally, an overlapping bypass diode configuration has a slight advantage over a non-overlapping bypass diode configuration.

\section{Reference}

[1] E. E. Yousef Mahmoud, "Accuracy Improvement of the PV Model," in IEEE TRANSACTIONS ON SUSTAINABLE ENERGY, VOL 3, July 2015.

[2] H. S. Rauschenbachr, Solar Cell Array Design Handbook, New: Van Nostrand Reinhold, 1980.

[3] J. Perlin, From Space To Earth(The Story Of Solar Electricity), London: Harvard University Press, 1999.

[4] J. R. G. a. E. R. F. Marcelo Gradella Villalva, "Comprehensive Approach to Modeling and Simulation," in IEEE TRANSACTIONS ON POWER ELECTRONICS VOL. 24, NO.5, May 2009.

[5] J. G. E. F. M.G. Villalva, "Comprehensive approach to modeling and simulation of photovoltaic arrays," in IEEE Trans. power electron. 24 (5) 1198-1208, 2009.

[6] J. F. M.C Alonso Barc, "Experimental study of mismatch and shading effects in the IV characteristic of a photovoltaic module," in Solar Energy Materials \& Solar Cells 90 329340, 2009.

[7] G. M, Page-485,Renewable and Efficient Electric Power Systems, A JOHN WILEY \& SONS.

[8] A. S.-G. C. C. a. J. C. E. Díaz-Dorado, "Influence of the shadows in photovoltaic systems with different configurations of bypass diodes.," in International Symposium on Power Electronics, Electrical Drives, Automation and Motion, 2010.

[9] R. T. P. R. Dexso Sera, "PV panel model based on datasheet values," in IEEE Int. Symp. Ind.Electron. (ISIE), 2007.

[10] A. C. d. W. a. W. G. v. S. Boudewijn B. Pannebakker, Photovoltaics in the shade: one bypass diode per solar, PROGRESS IN PHOTOVOLTAICS: RESEARCH AND APPLICATIONS Prog. Photovolt: Res. Appl., 2017.

[11] Y. R. F. M. Bellia H, "A detailed modeling of photovoltaic module using MATLAB," in Astronomy and Geophysics, 3, 5361, 2014.

[12] R. T. P. R. D. Sera, "PV panel model based on datasheet values," in Proceedings of the IEEE International Symposium on Industrial Electronics (ISIE) 7, pp. 2392-2396, 2007.

[13] J. G. E. F. M.G. Villalva, "Comprehensive approach to modeling and simulation of photovoltaic arrays," in IEEE Trans. power electron. 24 (5) 1198-1208, 2009. 